\title{
Causes of suppurative keratitis in Ghana
}

\author{
Maria Hagan, Elizabeth Wright, Mercy Newman, Paul Dolin, Gordon Johnson
}

\begin{abstract}
Aims-Suppurative keratitis is a serious problem in all tropical countries, but very little information is available about the causative organisms in Africa. The objectives were to identify the causative organisms and the proportion of cases caused by fungi in southern Ghana, and to determine whether correct decisions about treatment could be made on the basis of Gram stain in the eye clinic.

Methods-Scrapings were taken from corneal ulcers of consecutive new patients presenting at Korle Bu Hospital, Accra, and inoculated on 'chocolate' and Sabouraud's agars. Further scrapings were taken for Gram staining and interpretation in the eye clinic. Duplicate slides were assessed by an experienced microbiologist in the UK.

Results-One or more organisms were cultured from 114 of 199 patients $(57 \cdot 3 \%$ ), the most common being Fusarium species, Pseudomonas aeruginosa, and Staphylococcus epidermidis. Fungi, alone or in combination, were isolated from $56 \%$ of the patients who had positive cultures. In total, 122 patients $(61 \cdot 3 \%)$ had their treatment either determined or altered based on the results of the microbiological diagnosis; in 87 of these solely on the basis of direct microscopic examination.

Conclusions-Infection by filamentous fungi accounted for more than half of the ulcers from which cultures were obtained. Both training in technique and experience in interpretation are necessary for microscopy based diagnosis by staff in the clinic to be of greatest value. Direct microscopy was particularly useful for detecting fungi.
\end{abstract}

Korle Bu Teaching Hospital, University of Ghana, Accra, Ghana M Hagan

M Newman

Worthing Hospital, Park Avenue, Worthing, England E Wright

Institute of Ophthalmology, Department of Preventive Ophthalmology, London P Dolin G Johnson

Correspondence to: Dr Gordon Johnson, Institute of Ophthalmology, Department of Preventive Ophthalmology, Bath Street, London EC1V 9EL.

Accepted for publication 9 August 1995 account for $35 \%$ of the isolates in microbial keratitis. $^{2}$ In Bangladesh the proportion is between $36 \%$ and $40 \%,{ }^{34}$ in southern India temperate climates. In south Florida fungi
$30 \%$ are fungi, ${ }^{5}$ and in Nepal $17 \% .^{6}$ In temperate climates such as Britain ${ }^{7}$ and northern United States, ${ }^{8}$ the proportion of fungi causing suppurative keratitis is very small. Similarly, at the high altitude of Johannesburg, South Africa, between $2 \cdot 1 \%$ and $2 \cdot 3 \%{ }^{9}{ }^{10}$ were caused by fungi, representing very few individual cases. There is a report of 21 cases of mycotic keratitis from Nigeria in $1976,{ }^{11}$ but very little information is otherwise available from sub-Saharan Africa.

Usually no appropriate antibiotics or ophthalmic antifungal agents are available, especially for treating an ulcer at a district level. Yet, paradoxically, ophthalmic corticosteroid preparations are freely available in some countries. An additional factor is that many people go to the traditional healer first, resulting in further delay and sometimes damage to the cornea.

A useful development has been the demonstration by Williams and associates that a simple microbiological laboratory could be established in Bangladesh and make a substantial difference to accuracy of management of corneal suppuration. ${ }^{12}$ of 58 cases which were culture positive the results could have been anticipated in 47 on the basis of Gram stain alone.

In Ghana blinding suppurative keratitis is a major problem. At the same time approximately 120 nurses have now completed a 1 year training for an ophthalmic nursing diploma, offering potential for greatly improved primary and secondary care. These graduates are working throughout the country in an extended role, often providing the only secondary eye care in district hospitals. It is, therefore, important that they are assisted to have a logical approach to these ulcers and to be provided with some essential medication for prophylaxis and treatment.

The primary purpose of this investigation has, therefore, been to determine the actual organisms causing suppurative corneal ulceration, and the proportion of cases caused by fungi, in southern Ghana. The second objective was to find out for how many cases a correct decision regarding treatment could be made in the eye clinic on the basis of Gram stain alone.

The long term aim is to develop and test appropriate and practical methods of prophylaxis and management for suppurative corneal ulceration at a community level, using paramedical and primary health care workers and a simple protocol with a limited choice of medications.

\section{Methods}

SUBJECTS

Consecutive new patients presenting to the 
Eye Unit of Korle Bu Hospital, Accra, were entered into the study if they had clinical signs of established suppurative corneal infection with loss of epithelium over at least $2 \mathrm{~mm}$ diameter and underlying stromal infiltration. Patients were excluded if they refused investigation and treatment, had viral ulcers which were not secondarily infected, Mooren's ulcer or other peripheral ulcers, had had recent perforating trauma, were already under treatment at the department, or were neonates less than 28 days post partum.

\section{CLINICAL EXAMINATION}

When accepted into the study, each patient was assigned a number and a separate record form in addition to the regular hospital records. The patient's age, sex, occupation, and place of residence were entered. A history was taken of the circumstances in which the eye became infected, of predisposing factors, and any prior treatment received.

Using a slit-lamp, a qualified ophthalmologist or ophthalmic medical officer examined each case and made a drawing on the record form of the appearance when first seen, both a frontal view and corneal section to show the depth of the ulcer. Particular attention was paid to the size, depth, and edges of the ulcer and the greatest diameter was measured for future comparison. The presence and height of a hypopyon were recorded, together with other evidence of anterior chamber reaction or iris and lens involvement.

\section{CORNEAL SPECIMENS FOR CULTURE AND MICROSCOPY}

Local anaesthetic without preservative was instilled (oxybuprocaine eyedrops) and a sterile Kimura spatula was used to scrape the base and edges of the ulcer. This material was inoculated onto, firstly, a 'chocolate' (lysed blood) agar plate and, secondly, a Sabouraud agar slope. If the ulcer had obvious fungal features when viewed under the slit-lamp, an additional Sabouraud slope in a bijou bottle was inoculated to be sent directly to the mycologist in London.

Further corneal scrapings were then taken for smears on at least two glass microscope slides. These were labelled and allowed to dry in air. Slides were fixed in $95 \%$ methanol for 5 minutes and then stained in the clinic with routine Gram's method. One slide was examined under $\times 10, \times 40$, and finally under $\times 100$ (oil immersion) lenses, to identify bacteria, hyphae, and other fungal elements. The Gram stain findings were recorded in the patient's study record and in the hospital notes.

On the basis of the Gram stain, the organisms seen were classified into six categories: Gram positive cocci in clumps or clusters (staphylococci), Gram positive cocci in chains or diplococci (streptococci), Gram positive rods, Gram negative cocci, Gram negative rods, and fungal hyphae or yeast forms.
CLINICAL MANAGEMENT

A fixed protocol was established for initial treatment with both topical medication and subconjunctival injection based on the Gram stain result.

Rules were also established for initial treatment if no organisms were seen on the smear or the identification of the bacteria was in doubt. There were similar guidelines for modifications to the initial treatment, based on culture and sensitivity results or failure of response to initial treatment.

\section{FURTHER IDENTIFICATION OF ORGANISMS}

The culture plates and bottles were taken immediately to the microbiology laboratory at Korle $\mathrm{Bu}$ Hospital for incubation, identification, and testing of sensitivities according to standard methods. The duplicate slides were mailed in batches to the microbiologist in the UK. Initial cultures where fungi were suspected and secondary cultures of fungi grown in the laboratory and inoculated on Sabouraud slopes, were mailed, or taken in batches to the mycologist in London.

Where an eye was irretrievable, cultures were taken and the corneal disc was removed at the time of evisceration or enucleation. The corneal specimen itself was divided in half, one half for culture. The other half was fixed in formalin and sent to the Department of Pathology, Institute of Ophthalmology, London, for histology.

All the clinical details, results of progress, and results of Gram stain and culture were entered into a specially prepared database and analysed at the International Centre for Eye Health in London.

\section{Results}

A total of 207 consecutive cases presenting with suppurative keratitis were studied. Records were incomplete or specimens missing in eight cases, so that 199 cases have been analysed. The demographic and social characteristics of the 199 patients with suppurative keratitis are shown in Table 1 . The mean age was 36.3 years, the youngest patient was 1 year old while the oldest was aged 80 years. The majority $(69 \cdot 3 \%)$ of the patients were male. Twenty five different occupations were represented, the largest groups were students/teachers $(20 \cdot 1 \%)$ and traders $(19 \cdot 6 \%)$. Agricultural workers, an occupational group usually thought to be at particular risk of suppurative keratitis, accounted for $16 \cdot 1 \%$ of the patients.

An eye injury during the previous 3 months was reported by $77(39.2 \%)$ of the patients. The most common causes of eye trauma were wood, sticks, and twigs (18 patients), other vegetation (10 patients), and stones, sand, and dirt (17 patients). No eye injury was reported by $122(60 \cdot 8 \%)$ patients.

MICROBIOLOGICAL DIAGNOSIS BASED ON

CULTURE

One or more pathogens were cultured from the 
Table 1 Demographic and social characteristics of 199 patients with suppurative keratitis

\begin{tabular}{lrr}
\hline Characteristics & No & $\%$ \\
\hline Age (years) & & \\
<15 & 33 & $16 \cdot 6$ \\
$15-29$ & 51 & $25 \cdot 6$ \\
$30-44$ & 51 & $25 \cdot 6$ \\
$45+$ & 64 & $32 \cdot 2$ \\
Sex & 138 & \\
Male & 61 & $69 \cdot 3$ \\
Female & 160 & $30 \cdot 7$ \\
Place of residence & 7 & $80 \cdot 4$ \\
Accra region & 12 & $3 \cdot 5$ \\
Volta region & 16 & $6 \cdot 0$ \\
Central region & 4 & $8 \cdot 1$ \\
Eastern region & 32 & $2 \cdot 0$ \\
Not known & 14 & $16 \cdot 1$ \\
Occupation & 7 & $7 \cdot 0$ \\
Farming & 12 & $3 \cdot 5$ \\
Wood/stoneworker & 40 & $6 \cdot 0$ \\
Metal worker & 39 & $20 \cdot 1$ \\
Other factory workers & 14 & $19 \cdot 6$ \\
Student/teacher & $7 \cdot 1$ \\
Trader & 20 & $10 \cdot 0$ \\
Driver & 18 & $9 \cdot 1$ \\
Other & 3 & $1 \cdot 5$ \\
Retired/unemployed & 122 & $60 \cdot 8$ \\
Not known & 77 & $39 \cdot 2$ \\
Eye injury within previous 3 months & 18 & \\
No & 10 & \\
Yes & 17 & \\
Wood, stick, twig & 32 & \\
Other vegetable matter & & \\
Stone, sand, dirt & & \\
Other foreign body & & \\
\hline & & \\
\hline
\end{tabular}

corneal smears of 114 patients (57.3\%). Shown in Table 2 is the range of bacteria and fungi cultured. The most common organisms isolated were Fusarium species, Pseudomonas aeruginosa, and Staphylococcus epidermidis. A single pathogen only was cultured from 103 patients while two or more different pathogens were cultured from 11 patients. Categorising the cultured pathogens according to their Gram staining (Table 3) shows Gram positive

Table 2 Organisms cultured from corneal scraping taken from 199 patients with suppurative keratitis

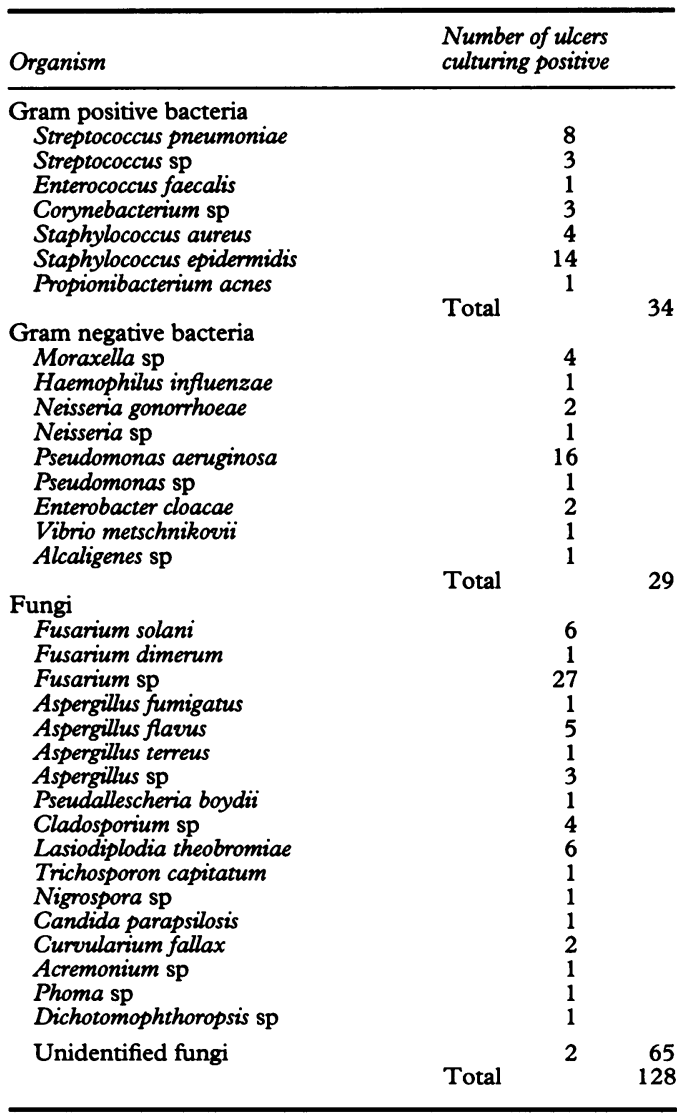

Table 3 Combinations of pathogens cultured

\begin{tabular}{lcr}
\hline Pathogen cultured & Patients & \multicolumn{1}{c}{$\%$} \\
\hline Gram +ve bacteria only & 25 & 12.6 \\
Gram - ve bacteria only & 22 & $11 \cdot 1$ \\
Fungi only & 56 & 28.1 \\
Gram +ve and - ve bacteria only & 3 & 1.5 \\
Gram +ve bacteria and fungi only & 4 & 2.0 \\
Gram - ve bacteria and fungi only & 2 & 1.0 \\
Gram +ve and -ve bacteria and 1 fungus & 1 & 0.5 \\
Gram +ve and -ve bacteria and 2 fungi & 1 & 0.5 \\
Nothing cultured & 85 & 42.7 \\
Total & 199 & 100.0 \\
\hline
\end{tabular}

bacteria were cultured from 34 patients, Gram negative bacteria from 29 patients, while fungi were grown from a total of 64 patients.

In one patient four different organisms were cultured, including two fungi: Staphylococcus epidermidis, Pseudomonas aeruginosa, Lasiodiplodia theobromiae, and Dichotomophthoropsis species. In another case three organisms were identified, Vibrio metschnikovii, an $\alpha$ haemolytic streptococcus, and a filamentous fungus which did not survive in transit for further identification.

No pathogen was cultured for $85(42 \cdot 7 \%)$ patients, although 52 of these patients had a pathogen identified by microscopic examination of a smear taken from their corneas. Overall, no pathogen was found either by microscopy or by culture for $33(16.6 \%)$ patients.

To determine why no pathogen was found for these 33 patients, possible explanatory factors were examined. No difference was found between the 33 patients and the remaining 166 patients for whom a pathogen was found with regard to use of eye medicines before assessment at the clinic, interval between onset of symptoms and attendance at the clinic, or diameter of epithelial defect or diameter of infiltrate in the affected eye. However, the groups did differ significantly in relation to the quality of the smear collected from the cornea for microbiological diagnosis. When the quality of the smear was categorised arbitrarily as poor, adequate, or good 19 of the $33(57.6 \%)$ patients with no pathogen found had a poor quality smear compared with 55 of the remaining $166(34.0 \%)$ patients $\left(\chi^{2}, \mathrm{p}=0.03\right)$.

\section{COMPARISON OF CULTURE BASED DIAGNOSIS} AND GRAM STAINING BASED DIAGNOSIS The microbiological diagnosis based on culture was compared with microscopic examination of smears taken directly from the cornea (Table 4). Of the 34 patients for whom Gram positive bacteria were cultured, 17 were identified correctly by direct microscopy in the ophthalmic clinic (sensitivity $=50 \%$ ), while for the remaining 17 cases Gram positive bacteria were either not detected or incorrectly identified by microscopy. Of the 29 patients from whom Gram negative bacteria were cultured, 13 were correctly identified by microscopy in the ophthalmic clinic (sensitivity $=45 \%$ ), and of the 64 patients from whom fungi were cultured, 34 were correctly identified by microscopy (sensitivity $=53 \%$ ).

Microscopy in the ophthalmic clinic often identified bacteria which were not cultured. 
Table 4 Evaluation of microscopy of Gram stained corneal smears when undertaken by ophthalmic clinic staff and by a medical microbiologist, compared with culture results

\begin{tabular}{|c|c|c|c|c|c|c|c|c|}
\hline \multirow[b]{2}{*}{ Pathogen } & \multirow[b]{2}{*}{ Culture } & \multirow[b]{2}{*}{ No } & \multicolumn{3}{|l|}{ Ophthalmology clinic staff } & \multicolumn{3}{|l|}{ Medical microbiologist } \\
\hline & & & $\begin{array}{l}\text { Seen by microscopy } \\
\text { (No) }\end{array}$ & $\begin{array}{l}\text { Sensitivity } \\
(\%)\end{array}$ & $\begin{array}{l}\text { Specificity } \\
(\%)\end{array}$ & $\begin{array}{l}\text { Seen by microscopy } \\
\text { (No) }\end{array}$ & $\begin{array}{l}\text { Sensitivity } \\
(\%)\end{array}$ & $\begin{array}{l}\text { Specificity } \\
(\%)\end{array}$ \\
\hline $\begin{array}{c}\text { Gram +ve } \\
\text { bacteria }\end{array}$ & $\begin{array}{l}\text { Yes } \\
\text { No }\end{array}$ & $\begin{array}{r}34 \\
165\end{array}$ & $\begin{array}{l}17 \\
40\end{array}$ & 50 & 76 & $\begin{array}{l}18 \\
21\end{array}$ & 53 & 87 \\
\hline Streptococcus & $\begin{array}{l}\text { Yes } \\
\text { No }\end{array}$ & $\begin{array}{r}12 \\
187\end{array}$ & 85 (GPDC, GPC, chains) & 67 & 76 & 93 (GPDC, GPC, chains) & 75 & 88 \\
\hline Staphylococcus & $\begin{array}{l}\text { Yes } \\
\text { No }\end{array}$ & $\begin{array}{r}18 \\
181\end{array}$ & 27 (GPC, chains) & 11 & 85 & 4 (GPC, chains) & 22 & 93 \\
\hline $\begin{array}{c}\text { Gram -ve } \\
\text { bacteria }\end{array}$ & $\begin{array}{l}\text { Yes } \\
\text { No }\end{array}$ & $\begin{array}{r}29 \\
170\end{array}$ & $\begin{array}{l}13 \\
28\end{array}$ & 45 & 84 & 22 & 76 & 92 \\
\hline Pseudomonas & $\begin{array}{l}\text { Yes } \\
\text { No }\end{array}$ & $\begin{array}{r}17 \\
182\end{array}$ & $\begin{array}{l}6 \\
28\end{array}$ & 35 & 85 & 12 (GNR) & 71 & 92 \\
\hline Fungi & $\begin{array}{l}\text { Yes } \\
\text { No }\end{array}$ & $\begin{array}{r}64 \\
135\end{array}$ & $\begin{array}{l}34 \text { (hyphae) } \\
17\end{array}$ & 53 & 87 & $\begin{array}{l}51 \text { (hyphae) } \\
10\end{array}$ & 80 & 93 \\
\hline
\end{tabular}

$\mathrm{GPDC}=\mathrm{Gram}$ positive diplococci $\mathrm{GPC}=\mathrm{Gram}$ positive cocci; $\mathrm{GNR}=\mathrm{Gram}$ negative rods.

Out of the 165 patients for whom no Gram positive bacteria were cultured, 40 were identified as having Gram positive bacteria by direct microscopy at the ophthalmic clinic (specificity $=76 \%$ ). Similarly, of the 170 patients for whom no Gram negative bacteria were cultured, 28 were identified by microscopy as having Gram negative bacteria (specificity $=84 \%$ ), and of the 135 patients for whom fungi were not cultured, 17 were identified by microscopy as having fungal hyphae by microscopy (specificity $=87 \%$ ).

To further explore the sensitivity and specificity of microscopy based diagnosis by ophthalmic clinic staff, the Gram stained smears were sent to Worthing, UK and examined by an experienced medical microbiologist. This was undertaken to differentiate the usefulness of microscopy under optimum conditions compared with that at the busy ophthalmic clinic in Accra. The sensitivity of microscopy based diagnosis improved when undertaken by the microbiologist (right hand side of Table 4). For fungi and Gram negative bacteria, microscopy was able to identify correctly $80 \%$ and $76 \%$ of culture positive cases, respectively. The specificity and false positive rate for microscopy based diagnosis also improved when undertaken by a microbiologist. This seemed to reflect the microbiologist's ability to differentiate between particulate matter and pathogens and between Gram positive and Gram negative bacteria, and the longer time available for the microbiologist to examine the slide.

\section{IMPACT OF MICROBIOLOGICAL DIAGNOSIS ON TREATMENT}

Twenty $(10 \cdot 1 \%)$ patients had their treatment

Table 5 Impact of microbiological assessment on treatment

\begin{tabular}{|c|c|c|c|c|c|c|}
\hline \multirow{3}{*}{$\begin{array}{l}\text { Treatment received } \\
\text { before assessment } \\
\text { No }\end{array}$} & & & \multicolumn{4}{|c|}{ Reasons for change in treatment } \\
\hline & \multicolumn{2}{|c|}{$\begin{array}{l}\text { Change of treatment } \\
\text { after assessment }\end{array}$} & $\begin{array}{l}\text { Microscopy } \\
\text { results only }\end{array}$ & $\begin{array}{l}\text { Culture } \\
\text { results only }\end{array}$ & $\begin{array}{l}\text { Microscopy and } \\
\text { culture results }\end{array}$ & $\begin{array}{l}\text { Other } \\
\text { reasons }\end{array}$ \\
\hline & \multirow{3}{*}{$\begin{array}{l}\text { No } \\
\text { Yes } \\
\text { No } \\
\text { Yes } \\
\text { No } \\
\text { Yes }\end{array}$} & \multirow{3}{*}{$\begin{array}{r}13 \\
20 \\
44 \\
116 \\
2 \\
4\end{array}$} & 14 & 3 & 1 & 2 \\
\hline Not known & & & 72 & 17 & 11 & 16 \\
\hline & & & 1 & 1 & 2 & 0 \\
\hline Total & $\begin{array}{l}\text { No } \\
\text { Yes }\end{array}$ & $\begin{array}{r}59 \\
140\end{array}$ & 87 & 21 & 14 & 18 \\
\hline
\end{tabular}

determined and $116(58.3 \%)$ patients had their treatment changed following the microbiological assessment (Table 5). Treatment was started or changed empirically in 18 patients, while in total $122(61.3 \%)$ had their treatment either determined or altered based on the results of the microbiological diagnosis. Of these, 87 had their treatment determined/changed solely on the basis of the direct microscopic examination. The microscopic diagnosis for these 87 patients was compared with diagnosis based on culture (Table 6). Ten of 11 Gram negative organisms, seven of 11 Gram negative organisms, and 29 of 33 fungal hyphae were correctly diagnosed by ophthalmic clinic staff using direct microscopy. The corresponding sensitivity of direct microscopy was $91 \%, 65 \%$, and $88 \%$ respectively for Gram positive organisms, Gram negative organisms, and fungi.

\section{Conclusion}

Before this study started, it had been estimated that fungi comprised approximately $10 \%$ of cases of suppurative corneal ulcer in Accra. In fact, they constituted either alone or in combination, over half $(56 \%)$ of those from whom a culture result was obtained - as high a proportion as has been recorded anywhere so far. From the published reports, it is apparent that there is a gradual increase in the proportion of suppurative keratitis due to fungus as one goes from higher latitudes in the northen hemisphere towards the equator. There is also a general tendency for a greater number of fungal species to be isolated and identified in tropical latitudes, although some published studies are much more comprehensive than others. Accra is not only at $5.5^{\circ}$ latitude north and hot, but also in general has very humid conditions which may be expected to encourage the growth of filamentous fungi in the environment.

Fusarium was the commonest genus of fungus identified in Ghana. In this respect, Ghana resembles the United States rather than India, Nepal, or Bangladesh, where Aspergillus has so far been the commonest genus reported. This is further evidence for geographical variation in the distribution of fungi pathogenic for the eye, which in turn influences the choice of treatment. It is also interesting that the 
Table 6 Evaluation of microscopy, when undertaken by ophthalmic clinic staff, and culture results for 87 patients for whom microscopy findings directly resulted in commencement or change of treatment

\begin{tabular}{lllllll}
\hline Pathogen & Culture & No & Seen by microscopy (No) & Sensitivity (\%) & Specificity (\%) \\
\hline Gram +ve bacteria & Yes & 11 & 10 & 91 & 68 \\
Gram -ve bacteria & No & 76 & 24 & 65 & 76 \\
Yes & 11 & 7 & & 72 \\
Fungi & No & 76 & 18 & 88 & 72 \\
& Yes & 33 & 29 & & \\
\hline
\end{tabular}

predominant organism in south Florida has changed over time, from Fusarium solani between 1959 and 1977, giving way to Fusarium oxysporum between 1982 and $1992 .^{13}$ From the present report and other published reports, it is clear that it is predominantly filamentous fungi, not yeasts, that cause infection in the eye in tropical climates.

Agricultural occupation was uncommonly associated with suppurative infection in Ghana, contrary to reports from other regions. This was true also when fungal infections were considered in isolation from bacterial infections. Of 63 proved fungal cases, $12(19 \%)$ were students, 12 traders, and only eight $(12 \cdot 7 \%)$ were farmers.

The microbiologist's results show microscopy is particularly useful for the identification of fungi and Gram negative bacteria (sensitivity $=80 \%$ and $76 \%$, specificity $=93 \%$ and $92 \%$ respectively). The reduced value of the technique when undertaken by staff at the ophthalmic clinic in Ghana indicates that clinic staff required more thorough training and retraining than was thought to be necessary at the start of this study. For microscopy to have its maximal application, the slide must evidently be read by a person trained and experienced in microscopy and the necessary time must be available in a busy clinic

False positive cultures tended to be of Gram positive species, such as Staphylococcus epidermidis, which may be contaminants from the normal flora of the tear film and eyelids.

What is the reason for no culture being obtained on 85 scrapings, and no pathogens by either microscopy or culture in 33? It appears that the material obtained was too small in some of these scrapings, although emphasis was continually placed on sufficiently vigorous scraping in the training and review sessions. Forty five per cent of cases in south Florida were culture negative, and this was attributed to partial previous treatment with antibiotics or antifungals. ${ }^{2}$ The prevalence of previous treatment was similar in culture negative and culture positive cases in the present study. It is possible that some of the culture negative cases could be accounted for by anaerobic organisms or by Acanthamoeba. Appropriate culture methods have therefore been introduced and a search is being made for these organisms.

The next stages of this programme will be to determine the sensitivity of the fungal isolates to simple antifungal substances which could potentially be made available at a reasonable price in isolated situations in tropical countries; to decide the optimum antibacterial and antifungal agents for the organisms isolated; and to establish trials of the simple agents with optimum regimes for prophylaxis after injury and of early treatment.

The identification by Yvonne Clayton of fungal isolates is gratefully acknowledged. We thank Alison McCartney for the histological examinations, and Christine Ntim-Ampousah, Vera Ofri-Darko, Agatha Aboe, Akua Brobbey, Elizabeth OforiOfri-Darko, Agatha Aboe, Akua Brobbey, Elizabeth OforiMante, and Francis Codjoe for their assistance
of clinical data and identification of organisms.

This study was supported by grants from the British Council
Thingal data and identification of organisms. for Prevention of Blindness.

1 Thomas PA Mycotic keratitis - an underestimated mycosis. F Med Vet Mycol 1994; 32: 235-56.

2 Liesegang TJ, Forster RK. Spectrum of microbial keratitis in South Florida. Am $\mathcal{F}$ Ophthalmol 1980; 90: 38-47.

3 Williams G, McClellan K, Billson F. Suppurative keratitis in Bangladesh: the value of Gram stain in planning management. Int Ophthalmol 1991; 15: 131-5.

4 Dunlop AA, Wright ED, Howlader SA, Nazrul I, Husain R, McClellan $\mathrm{K}$, et al. Suppurative corneal ulceration in Bangladesh. A study of 142 cases examining the microbiological diagnosis, clinical and epidemiological features biological diagnosis, clinical and epidemiological features of bacterial and fin $105-10$.

5 Thomas PA. Keratomycosis (mycotic keratitis). Baillière's clinical tropical medicine and communicable diseases. London: Baillière, 1989; 4: 269-86.

6 Upadhyay MP, Karmachanya PCD, Koirala S, Tuladhar NR, Bryan LE, Smolin G, et al. Epidemiologic characteristics, predisposing factors, and etiologic diagnosis of corneal ulceration in Nepal. Am f Ophthalmol 1991; 111. 92-9.

7 Coster DJ, Wilhelmus K, Peacock J, Jones BR. Suppurative keratitis in London. IVth Congress of the European Society of Ophthalmology. Royal Society of Medicine Iociety of Ophthalmology. Royal Society of Medicine London, 1981: 395-8.

8 Asbell P, Stenson S. Ulcerative keratitis. Survey of 30 years laboratory experience. Arch Ophthalmol 1982; 100 77-80.

9 Carmichael TR, Wolpert M, Koornhof HJ. Corneal ulceration at an urban African hospital. Br $\mathcal{F}$ Ophthalmol 1985 69: 920-6.

10 Ormerod LD. Causations and management of microbial keratitis in subtropical Africa. Ophthalmology 1987; 94: 1662-8.

11 Gugnani HC, Talwar RS, Njoku-Obi ANU, Kodilinye HC. Mycotic keratitis in Nigeria: a study of 21 cases. $B r f$ Ophthalmol 1976; 60: 607-13.

12 Williams G, Billson F, Husain R, Howlader SA, Islam N, McClellan K. Microbiological diagnosis of suppurative keratitis in Bangladesh. $\mathrm{Br} \mathcal{f}$ Ophthalmol 1987:71 315-21.

13 Rosa RH, Miller D, Alfonso EC. The changing spectrum of fungal keratitis in South Florida. Ophthalmology 1994, 101: 1005-13. 